\title{
PEOPLE MOVEMENT CHARACTERISTICS BASED ON AN EVACUATION TEST
}

\begin{abstract}
Modelling of the evacuation of people is the only method leading to a proper design of emergency escape routes from buildings. The background details necessary for modelling can only be obtained from actual incidents or evacuation tests. The paper presents the results of an evacuation test carried out in a university environment with respect to an announced evacuation. The introduction of the paper describes the scope of the test, physiological characteristics of the participants, the geometry and the environment. The analysis of the evacuation test focuses on the movement of people and the flow. The analysis of the results showed that the values recorded in the test are identical to those used in evacuation models; nevertheless, they differ from the calculation model and values used in the national prescriptive code.
\end{abstract}

Keywords: Evacuation test, movement, flow, fire safety.

\section{Introduction}

Details of human behaviour in various situations have been the subject of research since the 1950s [1], [2], [3] and [4]. Data collection is carried out using evacuation tests [5], [6] and [7] based on observations of current situations or actual incidents [8] and [9]. Only data from an actual incident allows creating a real view of human behaviour, but this is rare and practically non-repeatable. It is less risky to carry out an evacuation test from which a number of relevant data can be obtained. The range of information depends on the approach and scope of the observations during the test. Only one pre-selected value or set of values can be obtained from an evacuation test. According to Gwynne [10], human behaviour is influenced by the environment, procedures and geometry. This means that every situation is in fact genuine and, therefore, the implementation of evacuation tests, their monitoring and the analysis of the results are always beneficial.

\section{Scope, objectives and the methods of work}

The scope of the paper is an evacuation test. The results of an evacuation test could be expressed as "time travel" in terms of fire engineering. The following objectives are defined in accordance with the scope of this paper: to obtain data for analysing the movement of people; to obtain information on evacuation times and routes including selected sections of evacuation routes; to quantify the movement of people during an evacuation test; to compare the results with available and generally accepted values for behaviour and movement.

The basic method of work is itself an evacuation test. The test was carried out by evacuating volunteers from a building to a protected area. The evacuation was then repeated six times. Individual evacuations are referred to as Run 1, Run 2, Run 3, Run 4, Run 5 and Run 6. In terms of movement, we focus on movement mainly at checkpoints, for example stairs, doorways, fire barriers, etc. The test was monitored using hand-held video cameras (CAM designation 1-7) scattered throughout the evacuation route (Fig. 1). The total evacuation time was recorded directly during the evacuation test. Evacuation times, as well as the behaviour of people and other data, were obtained from a video analysis.

\subsection{Participants}

The test was conducted in a university environment. The evacuation test was conducted with the participation of fifty-four student volunteers, of 36 men and 18 women. The average age of volunteers was 22.7 years. The average height of men was $181 \mathrm{~cm}$. The average height of women was $168 \mathrm{~cm}$. The average weight of males was $79.9 \mathrm{~kg}$. The average weight of women was $58.2 \mathrm{~kg}$.

The volunteers were randomly divided into three basic groups labelled A, B, and C. Volunteers 53 and 54 arrived late, so they were only included in Runs 2-6. Three modifications to groups designated A1, A2, B1, B2, C1, C2 were made according to Table 1 due to this discrepancy. The groups were divided into three

\footnotetext{
* Martin Lopusniak, Dusan Katunsky

Department of Building Physics, Faculty of Civil Engineering, Technical University of Kosice, Slovakia

E-mail: dusan.katunsky@tuke.sk
} 
classrooms R1, R2, and R3 (Fig. 1). Each group started a run in a different room. Distribution of people in groups is shown also in Table 1.

The students who were quasi-studying started the evacuation immediately after being notified. Subsequently all persons were evacuated without further instruction using the fire escape stairs which led to the nearest building exit (Runs 1-4). In the case of Runs 5-6, participants were evacuated to the protected area R5 using only flat spaces.

Distribution of participants into groups during an evacuation test

Table 1

\begin{tabular}{|l|l|l|l|}
\hline Group & Persons & $\begin{array}{l}\text { Number of persons } \\
\text { in the group }\end{array}$ & Run \\
\hline A1 & $1-17$ & 17 & run $1,3,6$ \\
\hline A2 & $1-17 ; 53$ & 18 & run 2, 4, 5 \\
\hline B1 & $18-36 ; 40$ & 20 & run $1,2,4,5$ \\
\hline B2 & $18-36 ; 40 ; 53$ & 21 & run 3, 6 \\
\hline C1 & $37-39 ; 41-52$ & 15 & run 1,2 \\
\hline C2 & $37-39 ; 41-52 ; 54$ & 16 & run 3, 4, 5, 6 \\
\hline
\end{tabular}

Volunteers were instructed to move as quickly as possible but in a manner to avoid unwanted and unnecessary injuries.

\subsection{Environment}

The test was performed in a five storey building. All of the sample rooms were situated on the fifth floor and designated as R1, R2 and R3. Runs 5 and 6 were directed to a protected area designated $\mathrm{R} 5$, which is also situated on the fifth floor. The fire escape designated R4 contained a total of eighty-one stairs. During the test, areas were illuminated only by natural light. The floor plan dimensions, designation of rooms, doors, technical data rooms, hallways and stairs are shown in Fig. 1. The area of a standard flight of stairs is $3.6 \mathrm{~m}^{2}$. The length of one flight is $3.2 \mathrm{~m}$. The evacuation test did not include any artificial barriers. All volunteers were familiar with their surroundings.

During Runs 1 to 4, participants completed a route from rooms R1, R2, R3 through door D1, D2, and D3 (width $800 \mathrm{~mm}$, standard handle, opening against the direction of escape) to a corridor. It was followed by movement through door D4 (double door - fire door, wing width $2 \times 800 \mathrm{~mm}$, standard handle on the main wing, latch on the other wing, opening in the direction of escape) towards the staircase (R4). The descent to door D6 which led to the exit (width $900 \mathrm{~mm}$, standard handle, opening against the direction of escape) was completed in a short amount of time. The start of Runs 5 and 6 were identical to Runs 1-4, but the level movement (the corridor) led in the opposite direction to door D5 (same as D4).

\section{Results}

The results obtained from the evacuation test present two sets of data. The first set lists evacuation times. The second set contains parameters describing people's movement and flows.

\subsection{Evacuation times}

The first set of results presents total and partial evacuation times. Each designated evacuation time is associated with figures indicating the number of runs, for example $t_{2,3}\left(t_{2}\right.$ evacuation time for Run 3). The total and partial evacuation times of runs are listed in Table 2.
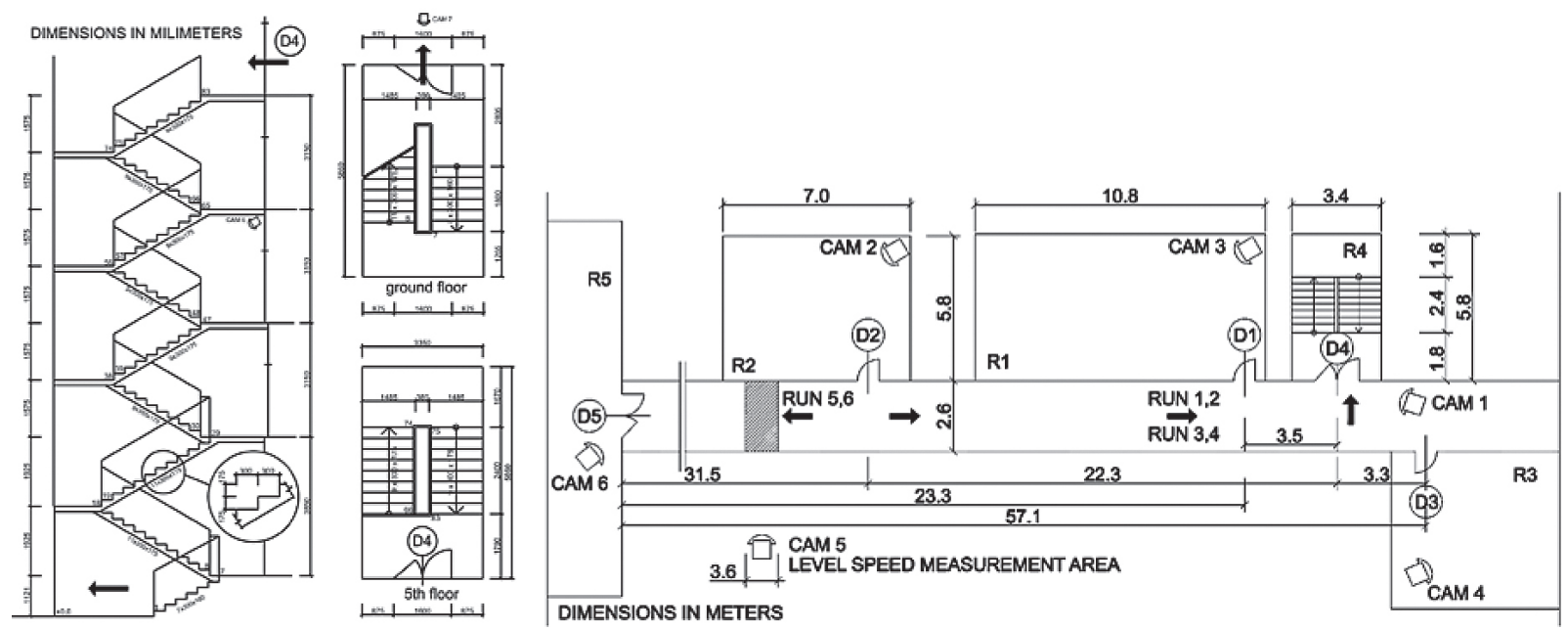

Fig. 1 Overall schematic view of space on the fifth floor and cameras' positions and cross section of the stairwell 


\begin{tabular}{|c|c|c|c|c|c|c|c|c|c|}
\hline Run number & Room R1 & Room R2 & Room R3 & $\begin{array}{l}\text { Evacuation } \\
\text { time }\end{array}$ & Run number & Room R1 & Room R2 & Room R3 & $\begin{array}{l}\text { Evacuation } \\
\text { time }\end{array}$ \\
\hline \multicolumn{5}{|c|}{ The total evacuation time $(\mathrm{ET}), \mathrm{t}_{1},(\mathrm{~s})$} & \multicolumn{5}{|c|}{ ET leaving room $\mathrm{R} 1, \mathrm{t}_{2}(\mathrm{~s})$} \\
\hline Run 1 & $\mathrm{C} 1$ & B1 & A1 & 84 & Run 1 & $\mathrm{C} 1$ & & & 16.5 \\
\hline Run 2 & $\mathrm{~A} 2$ & $\mathrm{C} 1$ & B1 & 89 & Run 2 & $\mathrm{~A} 2$ & & & 15.4 \\
\hline Run 3 & $\mathrm{~B} 2$ & A1 & $\mathrm{C} 2$ & 87 & Run 3 & $\mathrm{~B} 2$ & & & 21.9 \\
\hline Run 4 & $\mathrm{C} 2$ & B1 & $\mathrm{A} 2$ & 95 & Run 4 & $\mathrm{C} 2$ & & & 15.6 \\
\hline Run 5 & A2 & $\mathrm{C} 2$ & B1 & 53 & Run 5 & $\mathrm{~A} 2$ & & & 14.8 \\
\hline Run 6 & $\mathrm{~B} 2$ & A1 & $\mathrm{C} 2$ & 55 & Run 6 & $\mathrm{~B} 2$ & & & 18.8 \\
\hline \multicolumn{5}{|c|}{$\begin{array}{l}\text { ET for the last person to enter the door D4 to the staircase } \\
\text { (space R4), } \mathrm{t}_{3}(\mathrm{~s})\end{array}$} & \multicolumn{5}{|c|}{$\begin{array}{l}\text { ET for the first person to enter the door D4 to the staircase } \\
\text { (space } \mathrm{R} 4), \mathrm{t}_{4}(\mathrm{~s})\end{array}$} \\
\hline Run 1 & $\mathrm{C} 1$ & B1 & A1 & 37 & Run 1 & $\mathrm{C} 1$ & B1 & A1 & 3 \\
\hline Run 2 & $\mathrm{~A} 2$ & $\mathrm{C} 1$ & B1 & 38 & Run 2 & $\mathrm{~A} 2$ & $\mathrm{C} 1$ & B1 & 4.5 \\
\hline Run 3 & B2 & A1 & $\mathrm{C} 2$ & 35 & Run 3 & B2 & A1 & $\mathrm{C} 2$ & 5.2 \\
\hline Run 4 & $\mathrm{C} 2$ & B1 & $\mathrm{A} 2$ & 37 & Run 4 & $\mathrm{C} 2$ & B1 & $\mathrm{A} 2$ & 5 \\
\hline \multicolumn{5}{|c|}{ ET to pass door D4 by all people, $\mathrm{t}_{5}(\mathrm{~s})$} & \multicolumn{5}{|c|}{ ET to pass a flight of stairs by all people, $t_{8}(s)$} \\
\hline Run 1 & $\mathrm{C} 1$ & B1 & A1 & 34.7 & Run 1 & $\mathrm{C} 1$ & $\mathrm{~B} 1$ & A1 & 42.6 \\
\hline Run 2 & $\mathrm{~A} 2$ & $\mathrm{C} 1$ & B1 & 32.3 & Run 2 & $\mathrm{~A} 2$ & $\mathrm{C} 1$ & B1 & 40.0 \\
\hline Run 3 & $\mathrm{~B} 2$ & A1 & $\mathrm{C} 2$ & 32.3 & Run 3 & B2 & A1 & $\mathrm{C} 2$ & 35.3 \\
\hline Run 4 & $\mathrm{C} 2$ & $\mathrm{~B} 1$ & $\mathrm{~A} 2$ & 34.3 & Run 4 & $\mathrm{C} 2$ & B1 & $\mathrm{A} 2$ & 45.6 \\
\hline \multicolumn{5}{|c|}{ ET of the first person from $\mathrm{R} 2$ to enter the door D5, $\mathrm{t}_{7}(\mathrm{~s})$} & \multicolumn{5}{|c|}{ ET to pass door D5 by all people, $\mathrm{t}_{6}(\mathrm{~s})$} \\
\hline \multirow[t]{2}{*}{ Run 6} & B2 & A1 & $\mathrm{C} 2$ & 11.3 & Run 5 & A2 & $\mathrm{C} 2$ & B1 & 33.8 \\
\hline & & & & & Run 6 & B2 & A1 & $\mathrm{C} 2$ & 40.2 \\
\hline \multicolumn{5}{|c|}{ Evacuation time leaving room $\mathrm{R} 3, \mathrm{t}_{9}(\mathrm{~s})$} & \multicolumn{5}{|c|}{ ET to pass door D3 by all people from $\mathrm{R} 3, \mathrm{t}_{10}$ (s) } \\
\hline Run 5 & A2 & $\mathrm{C} 2$ & B1 & 15.2 & Run 5 & A2 & $\mathrm{C} 2$ & B1 & 13.8 \\
\hline Run 6 & $\mathrm{~B} 2$ & A1 & $\mathrm{C} 2$ & 11.3 & Run 6 & B2 & A1 & $\mathrm{C} 2$ & 10.0 \\
\hline \multicolumn{10}{|c|}{ ET to pass door D1 by all people from $\mathrm{R} 1, \mathrm{t}_{11}(\mathrm{~s})$} \\
\hline Run 5 & A2 & $\mathrm{C} 2$ & B1 & 10.8 & & & & & \\
\hline Run 6 & B2 & $\mathrm{A} 1$ & $\mathrm{C} 2$ & 15.1 & & & & & \\
\hline
\end{tabular}

Physical data were obtained from the evacuation test. This comparison showed that the total evacuation time for Runs 1 to 4 ranged from $t_{1}=84 \mathrm{~s}-95 \mathrm{~s}$. The average evacuation time of all four runs is $t_{1, \text { avg }}=88.75 \mathrm{~s}$. Runs 5 and 6 were $t_{1,5}=53 \mathrm{~s}$ and $t_{1,6}$ $=55 \mathrm{~s}$. Slight variations of time were probably caused by a change in the number or nature of persons located in different rooms. Divergence times are also a natural phenomenon since no person is able to behave naturally whilst performing the same, absolutely identical action.

\subsection{General characteristics of the evacuation}

Evacuation started immediately after the announcement. Response times were zero. Increased activity was evident throughout the group, as well as striving for the fastest and most efficient movement and exit from the building. No specific activities or problems were reported from the start of the evacuation until reaching door D4. Here an increased concentration of people was recorded before continuing to the staircase, which was smooth and again without any problems. Movement through the door D4, the movement in the rooms and the movement on the stair are the most significant parts of the evacuation, which influence the evacuation time.

Tables and chairs caused the greatest obstruction to the flow of movement. The space between tables caused people to queue, which reduced the tendency of bottlenecking at the door. However, the rooms were not fully occupied and it is necessary to state that the answer to the movement and behaviour in the room when fully occupied or over-occupied is unknown. The answer to the movement and behaviour in the room with variable table and equipment layouts is also unknown. In Table 2, labelled $t_{2}(s)$ is presented with respect to time needed to empty room R1. 
Movement of persons down the stairs had a large influence on the evacuation during Runs $1-4$. During the descent, the group was spread out across the full length of the staircase. The first ten to twelve people were ordered in a row with significant distances between them. These people reached the highest values of staircase movement speed (Fig. 2a). Increasing time gradually increased the number of people on the same flight of stairs, while decreasing the rate of descent. The analogy to the speed of descent can be observed in terms of the number of persons on the staircase. However, places where movement was slowed down by one person resulted in an increase in the number of people on the flight of stairs. When people were arranged one after another, a maximum of three persons were found on each flight of stairs. It was necessary to arrange people next to each other as well as one after another where group sizes exceeded four persons on the flight of stairs. However, during all test runs never more than six people were recorded on a flight of stairs. The movement characteristics comply with the results of the work [11], especially in terms of sorting of people on the staircase.

\subsection{Speed of stair movement, stair flow}

Movement speed of persons is based on the general movement described above. Movement speeds of persons are presented as a speed over one flight of stairs. Speed is always referred to as the speed on the real length of the flight of stairs. To determine the descent, Run 1, Run 2 and Run 3 were analysed. The times to traverse one flight of stairs vary from $1.563 \mathrm{~s}$ to $2.953 \mathrm{~s}$. The average value is $2.14 \mathrm{~s}$.

The descent of persons is based on the measured time of the descent of a flight of stairs, which lead to the following range of $1.03-1.91 \mathrm{~m} / \mathrm{s}$. The speeds of selected individuals are presented in Fig. 2a. The average speed was $1.33 \mathrm{~m} / \mathrm{s}$ (median $1.26 \mathrm{~m} / \mathrm{s}$; mode $1.19 \mathrm{~m} / \mathrm{s}$ ). Probability distribution is presented in Fig. 2b. Average values are higher than commonly used values in evacuation models [12], or those available in the literature [7]. Moreover, these values are significantly higher than those for the examples presented in [8] or [13]. Also, the values are higher than those in a national prescriptive regulation [14], which is required for the evacuation calculation speed of movement down the stairs $(0.42 \mathrm{~m} / \mathrm{s})$. However, this value is expressed as the horizontal speed on the staircase.

The flow of people has been reported in Run 1 to 4 by the following values $1.25 \mathrm{p} / \mathrm{s}, 1.34 \mathrm{p} / \mathrm{s}, 1.51 \mathrm{p} / \mathrm{s}, 1.19 \mathrm{p} / \mathrm{s}$. The average flow of all runs is $1.32 \mathrm{p} / \mathrm{s}$, or $0.88 \mathrm{p} / \mathrm{s} / \mathrm{m}$ as the flow in one flight of stairs. The average flow of the escape route is described in the literature as a value of $1 \mathrm{p} / \mathrm{s}$ for a staircase width of $1100 \mathrm{~mm}$. This value is particularly valid for high-rise buildings. National prescriptive regulation [14] has a requirement of $0.5 \mathrm{p} / \mathrm{s}$ for a single evacuation unit $0.55 \mathrm{~m}$ wide. Multiplying this requirement by the width of the staircase provides a maximum value equal to
$1.25 \mathrm{p} / \mathrm{s}$. The average flow of the evacuation test was closer to the requirement for prescriptive regulation than for the speed of movement.

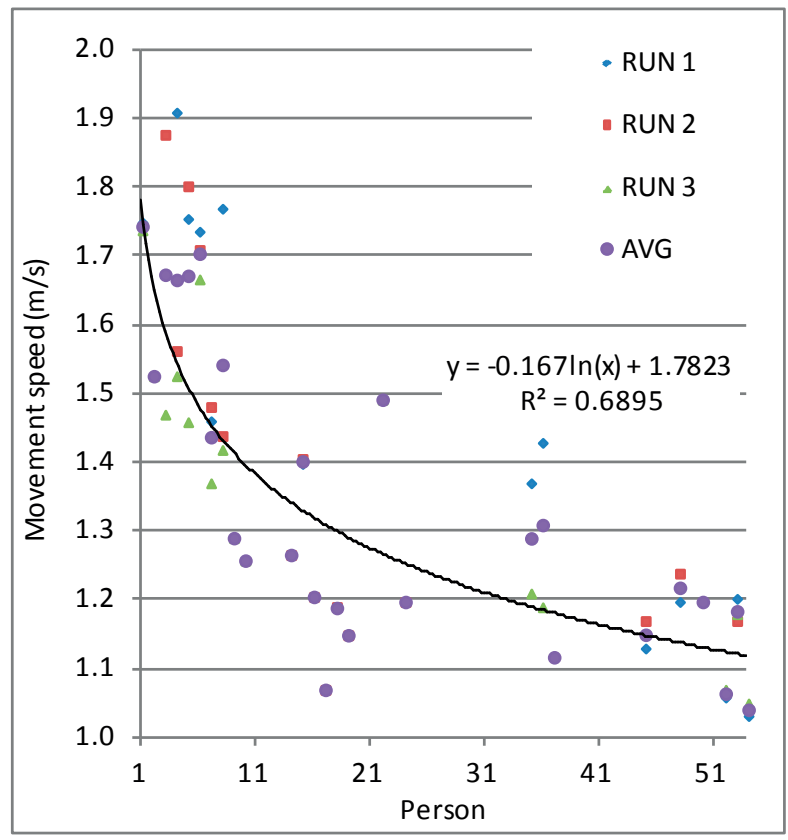

a)

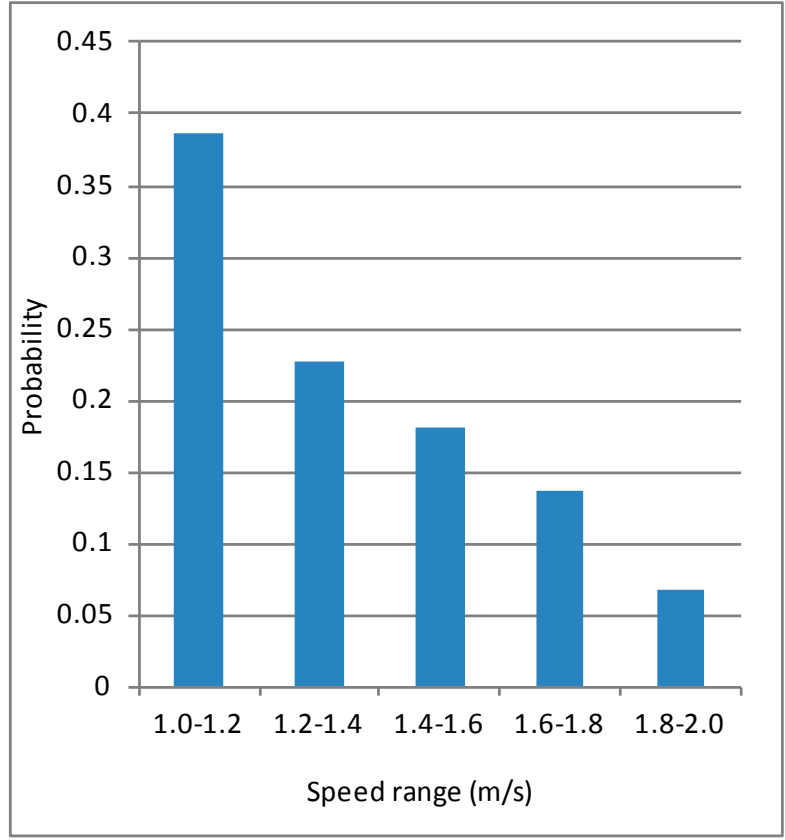

b)

Fig. 2 a) Speed of people on the flight of stairs in $\mathrm{m} / \mathrm{s}$ b) Probability distribution 


\subsection{Movement through the door, flow through the door}

Door D4 was selected to determine the flow through the door, because it directly accesses the staircase area and the protected area. Door transit time is shown in Table 2 as time $t_{5}$ and $\mathrm{t}_{6}$. At this time, the flow was calculated to be between 1.5 and $1.67 \mathrm{p} / \mathrm{s}$, with respective unit flows of 1.88 to $2.09 \mathrm{p} / \mathrm{m} / \mathrm{s}$. Door flow is fixed at a population density of $4 \mathrm{p} / \mathrm{m}^{2}$. The details of the door transit are shown in Fig. 4 (marked as RUN 2). The highest flow of people in a short time interval $(\mathrm{t}=5 \mathrm{~s}$ ) was $1.8 \mathrm{p} / \mathrm{s}$ (Fig. 4b; F RUN2). In contrast to the speed on the stairs, these data are consistent with the literature where the range for unit flow rate was reported to be from 1.25 to $2.0 \mathrm{p} / \mathrm{m} / \mathrm{s}$ according to its corresponding density [2], [15] and [16].
As far as the queuing and transition through the door are concerned, it was observed that people exited the door predominantly in a row (Fig. 3a). In a few cases two persons exited the door simultaneously. In such cases mutual coordination had to be facilitated (Fig. 3b). Such coordination was necessary even in the case of two women (Fig. 3c). A simultaneous exit of two men did not occur.

The door transit was the most significant factor of the test. From the point of view of evacuation modelling, an appropriate solution of this passage is a critical step. Comparison of various solutions of door transit of model buildingExodus (BE) [17] and the actual door transit during the test can serve as an example. BE allows two solutions in case of $800-\mathrm{mm}$ door. Either one node $(1 * 0.5 \mathrm{~m})$ or two nodes $(2 * 0.5 \mathrm{~m})$ are considered. None of

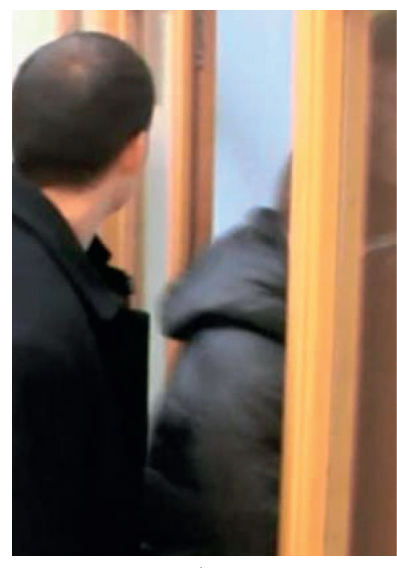

a)

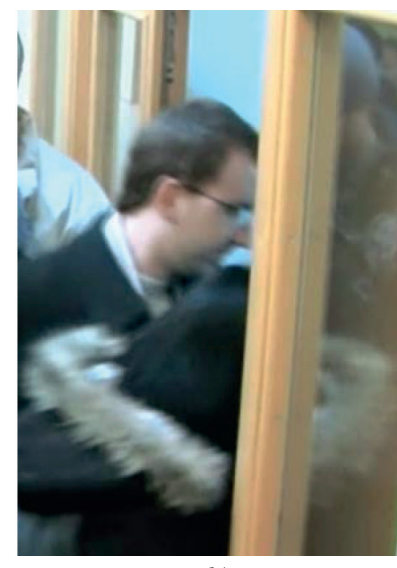

b)

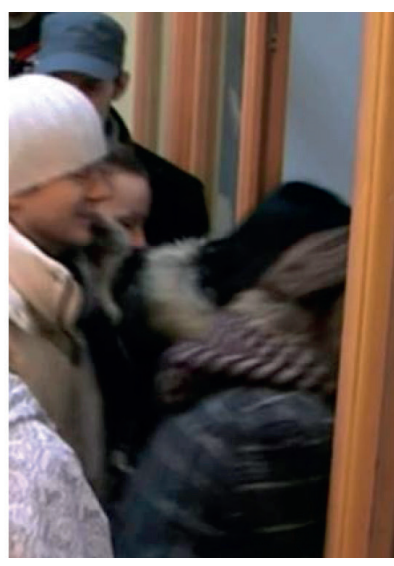

c)

Fig. 3 Movement through the door D4 a) in a row man-man; b) man-woman; c) woman-woman

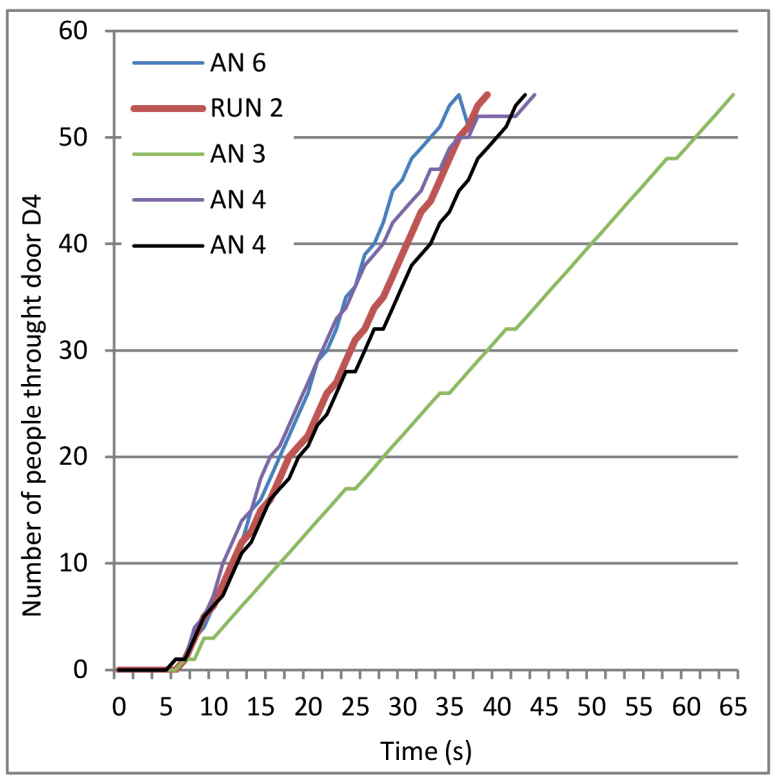

a)

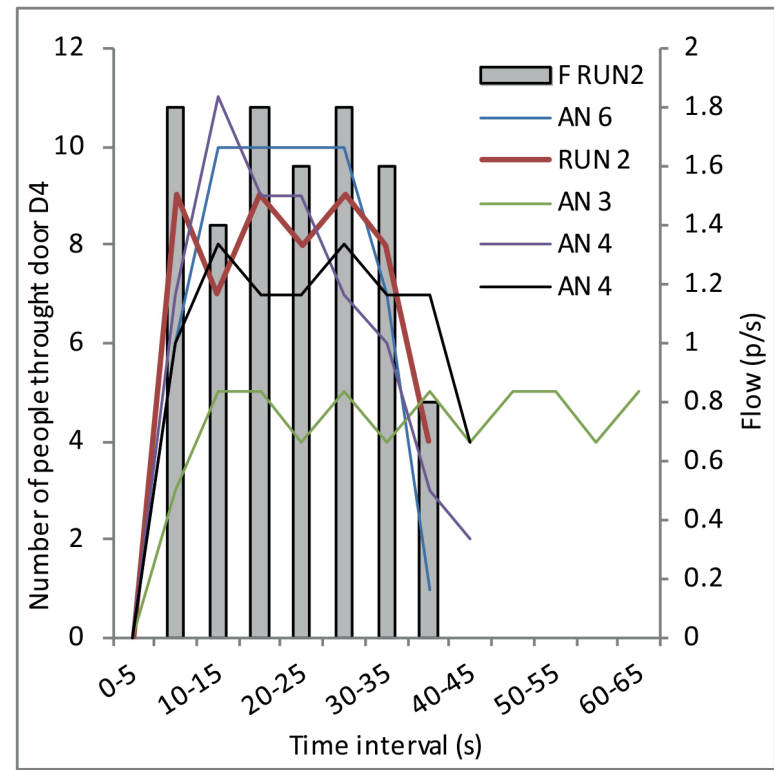

b)

Fig. 4 a) Cumulative course of the door flow b) The time interval door flow 
the solutions corresponds to the actual width of the door, which is $800 \mathrm{~mm}$. The adjustment of the flow is therefore necessary in order to reach coherence between the test and the evacuation. Accurately designed door showed coherence in the course and the cumulative representation of the transit time. As can be seen from results (Fig. 4a), a single-node solution does not correspond to reality (green line - AN4). Two nodes with incorrectly assigned flow also do not show coherence with the course of the door transit (blue - AN 6 and violet - AN 4). Correct solution is represented by the black line - AN 4, which is coherent to the actual course of the door transit during evacuation.

If the flow parameters are chosen correctly, people are ordered in front of the staircase in a way corresponding to the test. Ordering of people in front of the staircase in three different situations is illustrated in Fig. 5. In Fig. 5a, the ordering is the result of the course of door transit as represented by the green line (AN3). The number of people at the staircase is low and does not correspond to the test. Figure $5 \mathrm{~b}$ represents the blue line (AN6). The number of people is too high and also does not correspond to the test. Figure $5 \mathrm{c}$ represents the black line (AN4) and does correspond to the test.

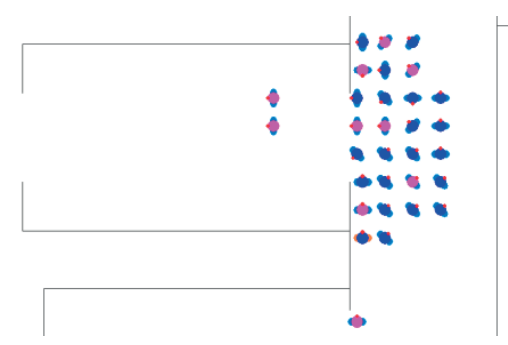

a)

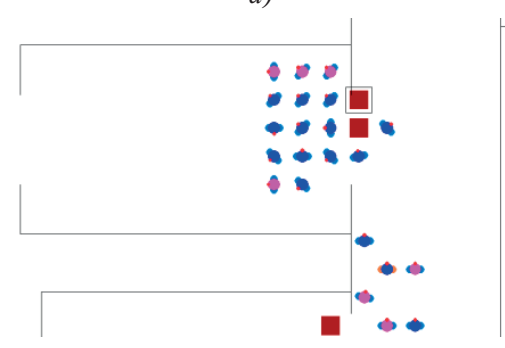

b)

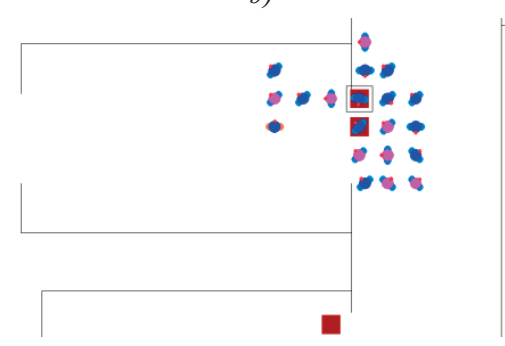

c)

Fig. 5 Concentration of people in front of the staircase for different model solutions

a) green $A N 3$; b) blue AN6; c) black AN4

\subsection{Level movement}

Level movement was measured over a $3.6 \mathrm{~m}$ long section. The section is shown in Fig. 1. Values range from 1.45 to 1.97 $\mathrm{m} / \mathrm{s}$. The average value is $1.56 \mathrm{~m} / \mathrm{s}$. According to Ando [18], the maximum walking speed is $1.6 \mathrm{~m} / \mathrm{s}$ for males and $1.4 \mathrm{~m} / \mathrm{s}$ for women. The test results are within this range. During the runs, the corridor flow was $1.66 \mathrm{p} / \mathrm{s}$, which is consistent with the flow through door D4. The maximum population density was $1.92 \mathrm{p} / \mathrm{m}^{2}$. The average concentration of people was in accordance with the Fruin density of C or D [2]. At this level there is no restriction to the movement of persons, hence the value for the speed of flat movement is high. During Run 6 an interesting situation occurred. The first 18 people ran to door D5. Their action was voluntary. The average speed of movement was $3.22 \mathrm{~m} / \mathrm{s}$.

\section{Discussion}

Evacuation modelling allows the usage of various input data. Movement parameters and flow capacities belong among the most significant. Peacock [7] recommends the use of a wider range of movement parameters rather than a narrow range or one average value. The evacuation model will therefore be more realistic.

The test results and the derived movement parameters and flow capacities have to be perceived as the upper limit values when used in evacuation scenarios and simulation calculations. The results of the test were influenced especially by the following facts: evacuation had been announced; participants were familiar with the environment; participants had no mental load (knowing that nothing was actually happening, which promoted a smooth and orderly evacuation); no other burdens (personal items, handbags, notebooks); physiological parameters, and health (the optimum age, weight, movement ability). The achieved results correspond with the data in literature describing the movement of people and flow capacity for similar groups of people, their composition and familiarity with the environment.

The test results do not implement the evacuation of people with disabilities. It is very difficult kind of evacuation tests. People with disabilities need to be included in the evacuation models but their movement characteristics have to be included correctly. For this purpose it is necessary to perform this kind of test in the future.

The results suggest the need of the update of movement parameters in the national prescriptive regulation. The values used for calculation are too low not only when compared to the test results but also in comparison to data used in other literature.

In any case, it is highly recommended to implement evacuation tests. Attention should be paid to different local constraints, which may inhibit movement or cause unexpected 
reactions. During evacuation tests, it is important to create conditions which would encourage the natural behaviour of people. The execution of small scale tests for specific activities such as corridor congestion, movement in densely populated rooms, movement in rooms with differing furniture layouts, and movement in overloaded rooms with people moving in opposite directions, is important for future analysis. Special attention is needed for preschool children, people with disabilities and the movement of emergency units going against the direction of the mainstream, and so on. In those areas, data has already been presented but the quantity is significantly smaller than data for a dominant population group.

\section{Conclusion}

The paper presents the results of an evacuation test focused on movement and flow parameters. The achieved results were compared to data presented in literature and prescriptive regulations. The values of movement parameters and flow capacities have to be perceived as upper limit values when used in evacuation scenarios and simulation calculations. The results are valid for persons up to 30 years of age, familiar with the environment. Mutual comparison of results showed that the movement speeds listed in the national technical standard are low and need to be updated.

\section{References}

[1] BRYAN, J. L.: A Selected Historical Review of Human Behaviour in Fire, J. of Fire Protection Engineering, 16, 4-10, 2002.

[2] FRUIN, J. J.: Pedestrian Planning and Design, Metropolitan Association of Urban Designers and Environmental Planners, New York, 1971.

[3] PAULS, J.: A Personal Perspective on Research, Consulting and Codes/Standards Development in Fire-related Human Behavior, 1969-1999, with an Emphasis on Space and Time Factors, Fire and Materials, 23(6), 265-272, 1999.

[4] PREDTECHENSKII, V. M., MILINSKII, A. I.: Planning for Foot Traffic Flow in Buildings, Amerind Publishing: New Delhi, 1978.

[5] WECKMAN, H., LEHTIMAKI, S., MANNIKKO, S.: Evacuation of a Theatre: Exercise vs. Calculations, Fire and Materials, 23(6), 357-361, 1999.

[6] WAS, J., ROBERT, L., MYSLIWIEC, W.: The Role of Proxemics in Pedestrian Evacuation: Comparison of Simulation and Experiment, Emergency Evacuation of People from Buildings, 377-384, 2011.

[7] PEACOCK, R. D, HOSKINS, B. L., KULIGOWSKI, E. D.: Overall and Local Movement Speeds During Fire Drill Evacuations in Buildings up to 31 Stories, Safety Science, 50 (8), 1655-1664, 2012.

[8] GAlEA, E. R., HUlSE, L., DAY, R., SIDDIQUi, A., SHARP, G., BOYCE, K., SUMMERFIELD, L., CANTER, D. D., MARSELLE, M., GREENALL, P. V.: The UK WTC 9/11 Evacuation Study: An Overview of the Methodologies Employed and Some Preliminary Analysis, Pedestrian and Evacuation Dynamics, 3-24, 2008.

[9] AVERILL, J. D., PEACOCK, R. D. \& KULIGOWSKI, E. D.: Analysis of the Evacuation of the World Trade Center Towers on September 11, 2001, Fire Technology, vol. 49, No. 1, 37-63, 2013.

[10] GWYNNE, S., GALEA, E. R., LAWRENCE, P. J., OWEN, M., FILIPPIDIS, L.: A Review of the Methodologies Used in the Computer Simulation of Evacuation from the Built Environment, Building and Environment, 34(6), 741-749, 1999.

[11] PAULS, J.: The SFPE Handbook of Fire Protection Engineering, National Fire Protection Association (NFPA), Quinci, 1995 , 3-285.

[12] GALEA, E. R.: Principles and Practise of Evacuation Modelling, CMS Press, London, 2009.

[13] GALEA, E. R., BLAKE, S.: Collection and Analysis of Human Behaviour Data Appearing in the Mass Media Relating to the Evacuation of the World Trade Centre Towers of 11 September 2001, Building Disaster Assessment Ground (BDAG), London, 2004.

[14] STN 920201-3. Fire Protection of Buildings: Escape Routes and Evacuation of Occupants, SUTN : Bratislava, 2000.

[15] HANKIN, B. D., WRIGHT, R. A.: Passenger Flows in Subways, Operational Research Quarterly, 9, 81-88, 1958.

[16] DAAMEN, W., HOOGENDOORN, S. P.: Emergency Door Capacity: Influence of Door Width, Population Composition and Stress Level, Fire Technology, 46, 1-17, 2010.

[17] FSEG. Building EXODUS. Version V5.0. FSEG, November, 2012.

[18] ANDO, K., OTA, H., OKI, T.: Forecasting the Flow of People, Railway Research Review, 45(8), 8-14, 1988. 